\title{
Kleine steden en reizende goden
}

AUTEURS Frederik Lamote

FOTOGRAFIE Frederik Lamote
In de schaduw van de grote Afrikaanse metropolen groeien honderden kleine steden verspreid over het Afrikaanse continent. Gedreven door eigen historische dynamieken, genereren deze kleine steden onzichtbare en verrassende religieuze netwerken die hen verbinden met Westerse grootsteden. Dit artikel bespreekt de link tussen globalisering, verstedelijking en religie in Techiman, een kleine Ghanese stad.

\section{Reizende goden}

Techiman is gelegen in Centraal-Ghana en werd gesticht omstreeks de 14de eeuw. Met vallen en opstaan is Techiman uitgegroeid tot een bloeiende handelsstad met ongeveer 82.000 inwoners. In en rond de stad liggen vele traditionele tempels. Deze religieuse plaatsen vormen niet enkel een brug tussen het heden en het verleden, maar ook tussen het lokale en het globale.

De traditionele tempels krijgen niet enkel Ghanezen ove de vloer, ook buitenlanders komen de goden consulteren. Een man en een vrouw van middelbare leeftijd reisden van Londen naar Techiman. Hij was geboren in Accra en groeide op in Londen. Zij had Indische roots, bracht haar jeugd door op het eiland Mauritius en migreerde nadien naar Londen. Daar runnen ze samen een internationaal kantoor gespecialiseerd in "Spiritual \& Psychic healing for the mind, body and spirit". Mensen van over heel Londen bezoeken hun kantoor op zoek naar hulp in relationele, financiële of gezondheidsproblemen. Om hun 'spirituele mogelijkheden' te vergroten, waren de twee naar Techiman gereisd, op zoek naar een krachtige god. De priester van de tempel, Nana Yaw Agyie, was helemaal niet verbaasd over het bezoek noch over de vraag van deze buitenlandse gasten. Na het uitvoeren van de nodige rituelen, vertrokken de twee Londenaars met het schrijn van een nieuwe god onder hun arm. De naam van hun nieuwe god was 'Tigare'. De roots van deze reizende god liggen echter niet in Techiman maar in Yipala, een klein dorpje in het noorden van Ghana. Nu prijkt het schrijn van
Tigare in een Londens kantoor. Tigare's transnationaal traject, van Yipala over Techiman naar Londen, is geen alleenstaand geval. Techiman fungeert als knooppunt van waaruit goden verspreid worden. De religieuze netwerken die hieruit ontstaan, hebben vertakkingen tot in grote wereldsteden. Het is echter belangrijk deze netwerken te lezen vanuit hun specifieke context, met in het achterhoofd het wereldbeeld dat dit soort transacties mogelijk maakt.

Voor velen, hoofdzakelijk niet-Westerlingen, wordt de zichtbare en tastbare wereld voorafgegaan door een onzichtbare wereld. Deze is bevolkt door een myriade van spirituele entiteiten, gaande van goede en slechte goden tot mythische figuren. De onzichtbare geesten en goden kunnen het leven in de zichtbare wereld beïnvloeden. Beide werelden staan dus met elkaar in verbinding en beïnvloeden elkaar. De verbindingen worden gelegd door de priesters en priesteressen die bemiddelen tussen beide werelden. Zij kennen het reilen en zeilen van de wispelturige spirituele wezens. Ze weten hoe ze de krachten van de goden moeten aanwenden om de vragen die de gelovigen hen voorleggen te beantwoorden. Deze verzoeken variëren van relationele conflicten of gezondheidsproblemen tot politieke en economische kwesties. Wanneer de goden niet langer in staat blijken om een antwoord te bieden op de behoeften en verzuchtingen van de gelovigen, wordt op zoek gegaan naar andere, meer daadkrachtige goden. De spirituele wereld is dus net als de materiële wereld een dynamische omgeving, gekenmerkt door verandering. Vaak staan verschuivingen in de spirituele wereld in verband met veranderingen in de materiële wereld.

Door de geschiedenis van de traditionele tempels in Techiman te analyseren en door de plaats van herkomst van de verschillende goden na te gaan, kunnen een aantal patronen bloot gelegd worden. Deze maken duidelijk hoe de zichtbare en de onzichtbare wereld in elkaar verweven zijn. Hieronder wordt de groei van de stad gelinkt aan religieuze veranderingen. De komst van nieuwe goden hangt samen met veranderingen in de stad. 


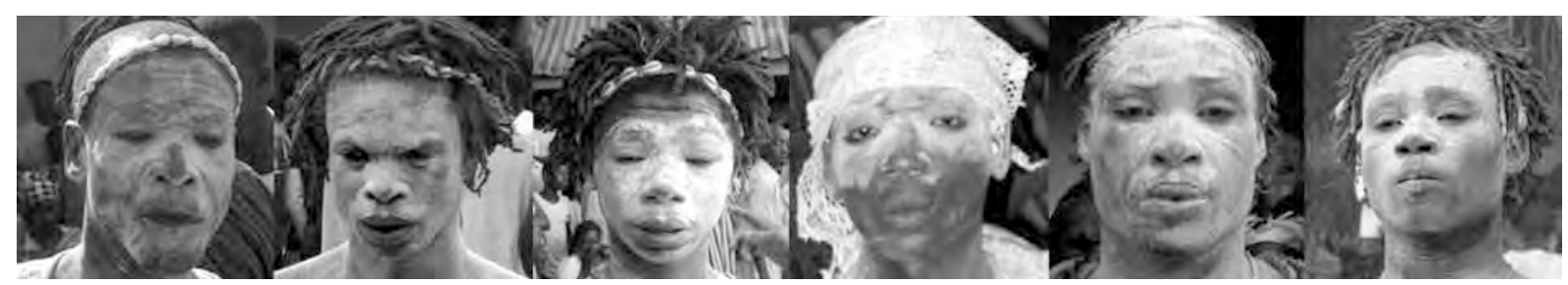

Priesters bezeten door goden uit het noorden.

\section{Oude goden, oude stad}

De oudste goden in Techiman zijn enkele honderden jaren oud. Het zijn lokale goden afkomstig uit de bossen, rivieren, rotsen en grotten die de stad omringen. De meest prominente goden waren afkomstig uit de rivier Tano. Deze heilige waterloop ontspringt even buiten Techiman, vloeit dan bijna helemaal rond de stad om vervolgens Techiman te verlaten. Op verschillende plaatsen in de rivier werden goden 'aangetroffen' en in een schrijn geplaatst. Een schrijn is een toegangspoort tot de spirituele wereld. Het is de manifestatie van het onzichtbare. De schrijnen van de Tano-goden zijn veelal koperen pannen gevuld met o.a. goud en klei uit de Tano-rivier. De Tano-goden hebben een belangrijke rol gespeeld in de politieke geschiedenis van Techiman en het roemrijke Bono-koninkrijk dat teloorging in het begin van de 18de eeuw. Vandaag spelen de Tano-goden een hoofdzakelijk ceremoniële rol. Door de sterke groei van de stad zijn de heilige plaatsen in de Tano-rivier verstedelijkt. Hierdoor verloren de Tano-goden hun kracht en daalde het vertrouwen in hen. Hun ceremoniële en politieke rol bleef behouden, maar hun sociale rol werd langzaam overgenomen door een jongere generatie goden

\section{wanneer de goden niet langer in staat blijken om een antwoord te bieden, wordt op zoek gegaan naar meer daadkrachtige goden}

De komst van de nieuwe generatie goden hangt nauw samen met de groei van de stad en de economische ontwikkelingen in koloniaal Ghana. In 1896 herbouwden de inwoners van Techiman hun stad na een verwoestende burgeroorlog. De heropbouw van Techiman betekende het begin van het huidige verstedelijkingsproces. Door de heropening van de markt migreerden vele handelaars en boeren uit het noorden van Ghana naar Techiman. Ze zorgden voor een gestage groei van de stad. Samen met de stijgende export van cacao, het belangrijkste export-product van koloniaal Ghana, creëerde de groei van de markt in Techiman heel wat rijkdom. Dit zorgde echter ook voor sociale wrijvingen. De rijke handelaars en boeren hadden schrik dat hun activiteiten zouden gedwarsboomd worden door heksen, gestuurd door jaloerse familieleden. De handelaars en boeren zochten bescherming in de tempels. Echter, de oude goden wisten geen raad met deze nieuwe vorm van angst voor 'economische hekserij'. De priesters moesten dus op zoek naar nieuwe daadkrachtige goden die een antwoord konden bieden op de veranderende spirituele behoeften.

\section{Noordelijke Goden in een groeiende stad}

De verstedelijking van Techiman was dus nefast voor de oude Tanogoden maar zorgde ook voor vernieuwing in de tempels. Priesters gingen op zoek naar nieuwe krachtige goden, wiens spirituele kracht onaangetast was door de verstedelijking. Deze vonden ze in het noorden van Ghana. Tot vandaag leeft in het zuiden van Ghana de perceptie dat het noorden van het land een onontwikkeld gebied is, waar de eeuwenoude tradities in stand worden gehouden en waar bijgevolg heel wat krachtige goden ronddwalen. Bovendien bestond in de jaren dertig het idee dat het noorden van Ghana vrij was van hekserij. Dit motiveerde vele priesters om naar het noorden te reizen en deze krachtige noordelijke goden naar het zuiden te halen. Door enkele rituele handelingen konden de goden uit het noorden getransfereerd worden naar het zuiden. In tegenstelling tot de Tano-goden, konden de noordijke goden wel een antwoord bieden op de stijgende angst voor hekserij. Dit leidde tot het ontstaan van verschillende religieuze cultussen rond goden uit het noorden: 'Nana Tongo', 'Mossi', 'Kunde', 'Aberewa', ... Vaak werden deze goden vanuit Techiman vespreid over de rest van Ghana. Vandaag nemen de religieuze netwerken die hieruit ontstaan zijn een globale dimensie aan. Ook Tigare, de god die de twee Londenaars kochten bij Nana Yaw Agyie, behoort tot deze generatie van goden.

De groei van de stad en de schaalvergroting van de lokale economie veroorzaakten een nieuwe maatschappelijke context die op haar beurt nieuwe goden veronderstelde. Het bezoek van de twee Londenaars moet dus bekeken worden vanuit de wisselwerking tussen verstedelijking, globalisatie en religieuze verandering. Sinds het begin van de jaren '90 is Techiman begonnen aan een exponentiële groei. De ondertussen internationale markt, de grootste van West-Afrika volgens de inwoners van Techiman, is het kloppende hart van de stad geworden. Nationale en internationale banken en bedrijven hebben hun weg naar Techiman gevonden. Op twintig jaar is de bevolking bijna verdrievoudigd. Daarmee is Techiman één van de snelst groeiende steden in Ghana. De schaalvergroting brengt Techiman meer dan ooit in contact met de globale wereld. Producten van over de hele wereld zijn verkrijgbaar op de markt in Techiman. Via de handel en de diaspora stromen nieuwe beelden en ideeën Techiman binnen. Deze vertalen zich in een sterk verlangen naar de 'moderniteit'. Dit verlangen komt ondermeer tot uiting in een nooit geziene cultus rond een nieuwe, moderne god, die binnengebracht werd door de 'blanke man' en afkomstig is uit een 'Westen': de Christelijke god.

\section{Moderne god(en) in een globale stad}

Hoewel het Christendom al sinds het begin van de 20ste eeuw aanwezig was in Techiman, vond de grote doorbraak pas plaats in de 


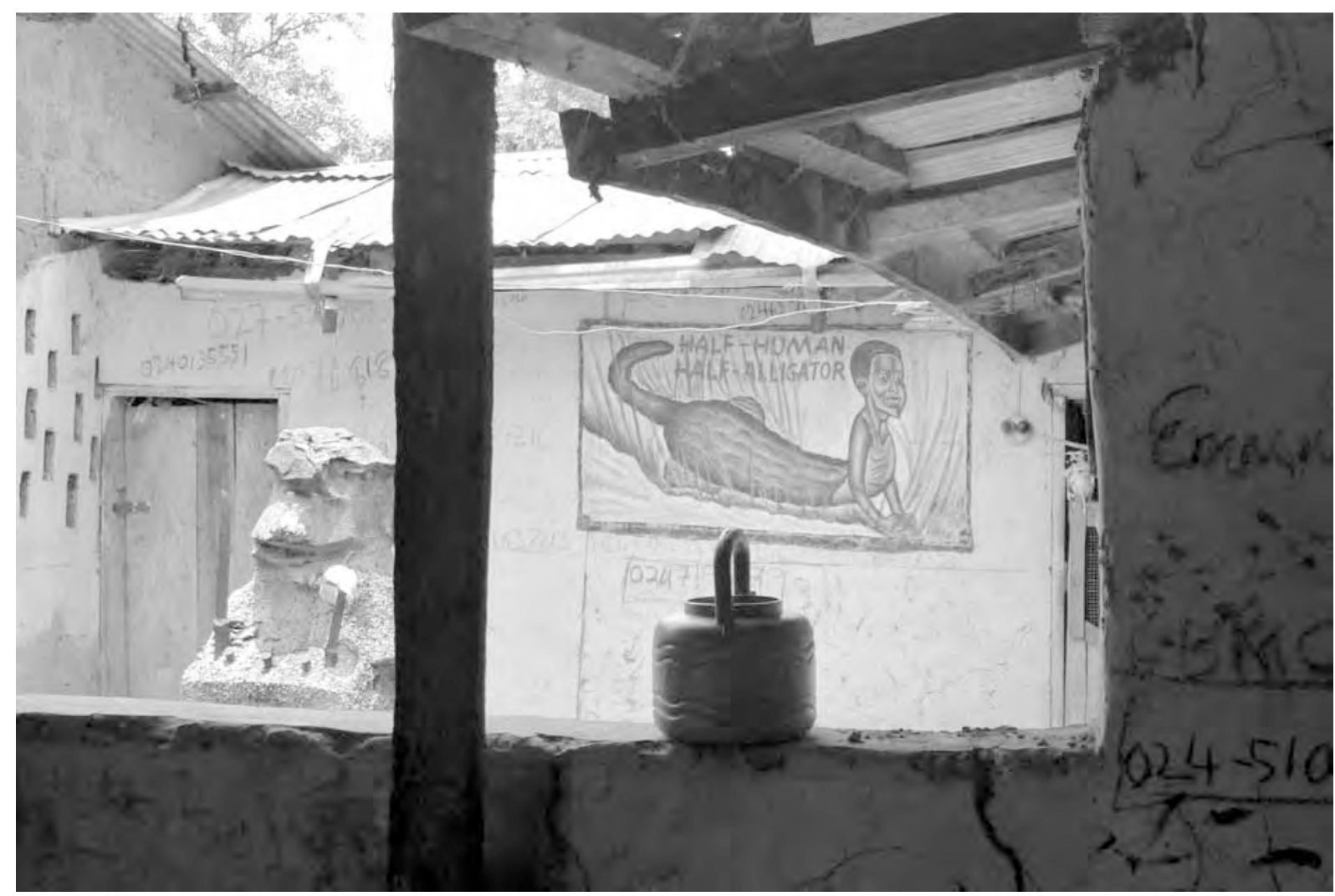

Nana Kwaku Bonsam in Amsterdam

jaren '80 en '90. Dit had veel te maken met de opkomst van de populaire Pinksterkerken. Deze spirituele kerken onderschrijven het lokale wereldbeeld dat naast de materiële, zichtbare wereld ook een spirituele, onzichtbare wereld bestaat. Zo kunnen de Pinksterkerken beter inspelen op de spirituele behoeften dan de 'klassieke' Protestantse en Katholieke kerken. De Pinksterbeweging postuleert dat slechts één goede god bestaat, namelijk de Christelijke god die op aarde vertegenwoordigd wordt door de 'heilige geest'. Belangrijk is dat de zeer populaire Pinksterkerken het bestaan van de traditionele goden niet ontkennen. Echter, de traditionele goden worden gediaboliseerd door de Pinksterkerken. Ze worden afgeschilderd als agenten van de duivel, als premoderne artefacten uit een donker verleden. Kerken met ronkende namen zoals 'Modern Ministry of God', 'Global Evangelist Church', 'God of Promised Land' of 'Christian Life International Centre' maken duidelijk dat de Christelijke 'heilige geest' een moderne, globale en stedelijke god is, in tegenstelling tot de traditionele goden. De traditionele religie staat dus onder druk. Mensen durven niet langer openlijk een traditionele priester te raadplegen. Bovendien kunnen de traditionele goden niet om met de gevolgen van de urbanisatie heen: de heilige plaatsen worden ingepalmd door de stad, taboes worden gebroken en het geloof in de kracht van de traditionale goden daalt. In tegenstelling tot de Christelijke god, weten de noordelijke goden geen raad met de nieuwe uitdagingen van het moderne leven in een stedelijke en globale context. Bovendien zijn de spirituele behoeften van de gelovigen gewijzigd. Migranten in Westerse steden contacteren via telefoon en internet Christelijke én traditionele priesters in Techiman. Ze vragen om bescherming tegen transnationale hekserij of vragen om spirituele hulp bij de zoektocht achter werk of verblijfspapieren. Ook in Techiman bezoeken vele mensen de kerken of, in het geheim, één van de traditionele tempels met deze vragen. Geconfronteerd met hun tanende populariteit en de wijzigende hulpvragen, gaan de Traditionele priesters op zoek naar nieuwe goden die overweg kunnen met veranderingen in de zichtbare wereld en een antwoord hebben op de nieuwe spirituele behoeften. Tijdens een rituele ceremonie in maart 2009 werd Nana Adankwa, een traditionale priester uit Techiman, bezeten door een god met de naam Frederic Boakye. De god onthulde dat hij afkomstig is uit Accra, de hoofdstad van Ghana, en boekhouden studeert aan de 'University of Ghana'. Bovendien sprak de god niet in de lokale taal Bono-Twi maar wel in het Engels. Enkele maanden later dook een andere Engelstalige god op.

\section{de god onthulde dat hij afkomstig is uit Accra, de hoofdstad van Ghana, en boekhouden studeert aan de 'University of Ghana'}

De god is afkomstig uit Londen en spreekt Engels met een bijhorende Britse tongval. De priester van deze god, Nana Kwaku Bonsam, is even beroemd als berucht in Ghana. Via zijn website (www.kwakubonsam. com) legt hij een link met zijn klanten in de diaspora en speelt hij in op de nieuwe spirituele behoeften. Ook de tempel van Nana Yaw Agyie, waar de twee Londenaars een god kwamen kopen, staat in nauw contact met de Westerse wereld. Eén van de muren van Nana Yaw Agyie's tempel is volgeschreven met lokale en internationale telefoonnummers. Zijn goden, zo stelt Nana yaw Agyie, kunnen in een fractie 


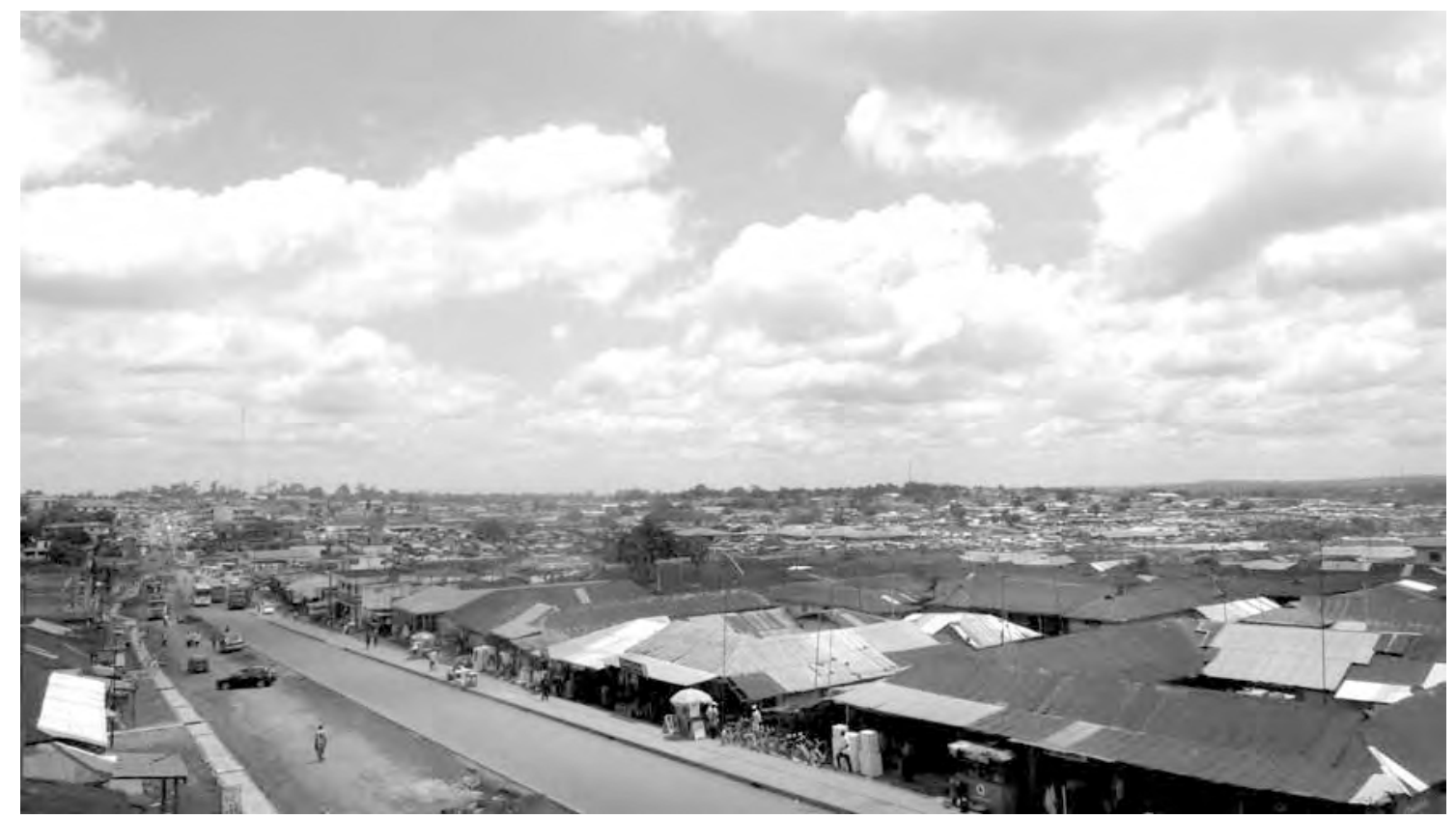

van een seconde naar eender welke plaats ter wereld reizen. In het zog van hun goden reizen ook priesters naar het buitenland. Nana Kwaku Bonsam opende in december 2010 een vestiging van zijn schrijn in Amsterdam. Een traditionele priester uit Techiman pendelt geregeld naar de Brusselse wijk Kuregem. In diezelfde wijk openden reeds verschillende Afrikaanse Pinksterkerken hun deuren. Regelmatig worden Afrikaanse priesters uitgenodigd om te preken en om mirakels ten tonele te brengen.

\section{Globalisatie, verstedelijking en religieuze innovatie}

Religieuze netwerken brengen zowel de eeuwenoude traditionale tempels als de nieuwere Christelijke Pinksterkerken van Techiman in directe verbinding met de globale wereld. Het bezoek van de twee Londenaars aan Nana Yaw Agyie's tempel kadert binnen dit proces van verstedelijking, globalisering en religieuze innovatie. Door de groei van de stad, globaliseren en verstedelijken de religieuze ruimtes van Techiman. De oude goden zijn afkomstig uit de rivieren rond de stad, de nieuw goden komen uit Afrikaanse en Westerse wereldsteden. Kerken en traditionale tempels zijn voor vele inwoners van Techiman de meest directe toegangspoort tot de Westerse stedelijke moderniteit geworden. Via de stedelijke en globale god(en) leggen de gelovigen contact met de globale wereld. Langs de andere kant reizen traditionele en Christelijke priesters en goden naar Westerse steden. Techimans reizende goden en hun priesters exporteren de stedelijke religiositeit naar de Westerse steden. Of hoe Techiman het stedelijk weefsel in Brussel en Londen mee vorm geeft. Globalisatie en verstedelijking zijn wederkerige processen.
Frederik Lamote (Frederik.Lamote@soc.kuleuven.be) werkt als antropoloog aan het Insitute for Anthropological Research on Africa, K.U.Leuven. Zijn onderzoek spitst zich toe op de antropologie van de stad. Hij analyseerde de autohandel tussen de Brusselse wijk Kuregem en Gare Petersen, een busstation in Dakar, (Senegal). Begin 2008 begon hij zijn doctoraatsonderzoek in Techiman, een kleine stad in CentraalGhana. Dit onderzoek bespreekt de wisselwerking tussen verstedelijking, globalisering en religieuze verandering.

\section{Literatuurselectie}

Allman, Jean, and John Parker (2005) Tongnaab : The History of a West African God. Bloomington: Indiana University Press.

De Boeck, Filip, and M. F Plissart (2004) Kinshasa. Tales of the Invisible City. Gent/Tervuren: Ludion/Koninklijk Museum voor Midden-Afrika. Hüwelmeier, Gertrud, and Kristine Krause, eds. (2010) Travelling Spirits: Migrants, Markets and Mobilities. New York: Routledge.

Lamote, Frederik, To be Published, "In a town like this, who is your god?" On Urbanisation, Religious Change and Popular Culture in Techiman, Ghana. Africa: Journal of the International Africa Institute.

Silverman, Raymond A. (1987) Historical Dimensions of Tano Worship among the Asante and Bono. In: The Golden Stool: Studies of the Asante wenter and periphery. E. Schildkrout and G. carol, eds, Vol. 65. New York: The american Museum of Natural History. 